\title{
HMGA1 participates in MHCC97H cell proliferation and invasion through the ILK/Akt/GSK3ß signaling pathway
}

\author{
LI LIU ${ }^{1}$, SHUANG ZHANG ${ }^{1}$, LEI HU ${ }^{1}$, LINHUA LIU ${ }^{1}$, WUHUA GUO ${ }^{1}$ and JIXIANG ZHANG ${ }^{1,2}$ \\ ${ }^{1}$ Department of Gastroenterology, The Second Affiliated Hospital of Nanchang University; \\ ${ }^{2}$ Jiangxi Key Laboratory of Molecular Medicine, Nanchang, Jiangxi 330006, P.R. China
}

Received April 7, 2016; Accepted March 10, 2017

DOI: $10.3892 / \mathrm{mmr} .2017 .7820$

\begin{abstract}
Hepatocellular carcinoma (HCC) is one of the major causes of cancer-related mortality, and the prognosis of HCC patients is unsatisfactory. It is known that the occurrence and development of HCC involves numerous genes, as well as various steps and stages in the pathological process. High mobility group AT-hook 1 (HMGA1) and integrin-linked kinase (ILK) may be overexpressed in HCC and may serve important roles in the development of cancer; however, the relationship between HMGA1 and ILK in HCC has not been examined. The present study demonstrated that inhibition of HMGA1 expression significantly decreased the levels of expression of ILK and the downstream elements phosphorylated (p)-Akt, p-glycogen synthase kinase $3 \beta$ (GSK3 $\beta$ ), matrix metalloproteinase (MMP)2, MMP9, CyclinD1 and c-Myc. Transfection with an ILK expression vector was able to recover the decreased expression of these downstream genes, and affected cell proliferation and apoptosis. In addition, results from Transwell and wound-healing experiments indicated that HMGA1 participates cell invasion and migration through the ILK/Akt/GSK3 $\beta$ pathway. The present study aimed to improve our understanding about the regulatory pathway involved in HCC and provides the basis for exploring HMGA1 inhibition as a therapy for patients with $\mathrm{HCC}$ and a new treatment strategy to prevent the development of HCC.
\end{abstract}

\section{Introduction}

Hepatocellular carcinoma (HCC) is the fifth most common malignancy and the third leading cause of cancer-related mortality worldwide (1). Despite major advancements in the diagnosis and treatment of HCC that have been made over the past few decades, the prognosis of patients with HCC remains

Correspondence to: Dr Jixiang Zhang, Department of Gastroenterology, The Second Affiliated Hospital of Nanchang University, 1 Minde Road, Nanchang, Jiangxi 330006, P.R. China

E-mail: jxzhang3@163.com

Key words: HMGA1, MHCC97H cells, proliferation, invasion, ILK/Akt/GSK-3 $\beta$ pathway unsatisfactory owing to its high recurrence rate, metastasis and poor therapeutic response $(2,3)$. Hepatocarcinogenesis is a complex, multi-step process that involves the accumulation of a number of genetic and epigenetic alterations (4). However, the molecular mechanisms of HCC pathogenesis are not yet fully understood. Therefore, investigations are urgently needed to explore new potential therapeutic targets and to elucidate the relevant molecular pathways involved in HCC progression and metastasis.

As a member of the high mobility group AT-hook (HMGA) protein family, HMGA1 is involved in a number of biological processes, such as stem cell self-renewal, cell proliferation, differentiation and neoplastic transformation $(5,6)$. Moreover, knockdown of HMGA1 expression may interfere with tumorigenic growth and may reduce cell invasion and migration capabilities in certain cancer cell lines $(7,8)$. A previous study revealed that HMGA1 is overexpressed in HCCs, and patients with a detectable level of HMGA1 mRNA in tumor sections have an increased risk of recurrence/metastasis and a shorter survival time (9). However, little is known about the role of HMGA1 in the development of HCC.

Integrin-linked kinase (ILK) is an intracellular serine/threonine protein kinase and adaptor protein that interacts with the cytoplasmic domains of $\beta 1$ and $\beta 3$ integrins (10). ILK regulates several cellular processes that are necessary for cancer progression, including cell proliferation, survival, migration and invasion, and angiogenesis (11-13). As a component of the phosphatidylinositol 3-kinase pathway, activated ILK is able to directly phosphorylate protein kinase B (PKB/Akt) on Ser473 and glycogen synthase kinase $3 \beta$ (GSK3 $\beta$ ) on Ser9, resulting in the activation of PKB/Akt and the inhibition of GSK3 $\beta$, respectively (14). Furthermore, ILK expression and activity are often elevated in human malignancies (15).

In a previous study, gene expression profile analysis of a MCF-7 breast epithelial cell line stably transfected with HMGA1 identified integrins and their signaling pathways as significantly upregulated genes (16). The present study focused on the ILK gene, as previous reports indicated its dysregulation in $\mathrm{HCC}$ and its involvement in promoting HCC cell growth, motility and invasion $(17,18)$. However, the association between HMGA1 and ILK in cancer has not yet been characterized. The present study hypothesized that there is an HMGA1/ILK axis in HCC and demonstrated that the knockdown of HMGA1 expression suppressed cell growth, 
migration and invasion, and induced apoptosis; these effects were reversed by overexpression of ILK in MHCC97H cell cultures. The antagonistic effects of ILK were attenuated in the presence of the Akt inhibitor MK2206. In addition, matrix metalloproteinase (MMP)2, MMP9, CyclinD1 and c-Myc were identified as possible downstream effectors of the HMGA1/ILK/Akt/GSK3 $\beta$ signaling pathway.

\section{Materials and methods}

Cell culture. The human HCC cell line MHCC97H was obtained from The Liver Cancer Institute of Fudan University (Shanghai, China) and cultured in Dulbecco's modified Eagle's medium (DMEM; Gibco; Thermo Fisher Scientific, Inc., Waltham, MA, USA) supplemented with $10 \%$ fetal bovine serum (FBS; HyClone; GE Healthcare Life Sciences, Logan, UT, USA), $100 \mathrm{U} / \mathrm{ml}$ penicillin and $100 \mu \mathrm{g} / \mathrm{ml}$ streptomycin. Cells were maintained at $37^{\circ} \mathrm{C}$ and $5 \% \mathrm{CO}_{2}$ in a humidified incubator.

Plasmids and lentiviral vector. The lentiviral short hairpin (sh) RNA vector against HMGA1 (shHMGA1, 5'-GATCCAGCGAA GTGCCAACACCTATTCAAG-AGATAGGTGTTGGCACTT CGCTTTTTTTA-3') and the scrambled control shRNA vector (shControl) were obtained from GeneChem Co., Ltd. (Shanghai, China). The ILK expression plasmid GV144-enhanced green fluorescent protein (EGFP)-ILK and the negative control plasmid GV144-EGFP were also from GeneChem Co., Ltd.

Plasmids and lentiviral transduction. $\mathrm{MHCC} 97 \mathrm{H}$ cells $\left(5 \times 10^{6}\right.$ cells $\left./ \mathrm{ml}, 37^{\circ} \mathrm{C}\right)$ were pre-transfected with $4 \mu \mathrm{g} / \mathrm{ml}$ GV144-EGFP-ILK or GV144-EGFP using FuGENE 6 Transfection Reagent (Roche Diagnostics GmbH, Mannheim, Germany), according to the manufacturer's protocol. Following $6 \mathrm{~h}$ incubation, the cells were transfected with LV-shHMGA1 or LV-shControl [multiplicity of infection $(\mathrm{MOI})=100$ ] for 2 days, according to Recombinant Lentivirus Operation Manual (GeneChem Co., Ltd.). The infection conditions were initial incubation for $10 \mathrm{~min}$ at room temperature followed by centrifugation at $1,900 \mathrm{x} \mathrm{g}$ for $30 \mathrm{~min}$ at $32^{\circ} \mathrm{C}$. Then the incubation for $24 \mathrm{~h}$ at $37^{\circ} \mathrm{C}$ with the Akt inhibitor MK2206 (5 $\mu \mathrm{M}$; Selleck Chemicals, Houston, TX, USA) or dimethylsulfoxide (DMSO) was carried out. There was a total of seven groups in these experiments: i) DMSO as Blank control; ii) shControl; iii) shHMGA1; iv) shHMGA1 + EGFP; v) shHMGA1 + ILK; vi) shHMGA1 + ILK + DMSO; and vii) shHMGA1 + ILK + MK2206. MOI 20, 50, 80, 100, 150 and 200 were also assessed. The knockdown efficiency of HMGA1, measured with reverse transcription-quantitative polymerase chain reaction (RT-qPCR), reached $95 \%$ when MOI was at 100 , where the cell viability was still at a high level.

$R T$ - $q P C R$. Total RNA was extracted $\left(2 \times 10^{5}\right.$ cells $\left./ \mathrm{ml}\right)$ from cultured MHCC $97 \mathrm{H}$ cells using TRIzol reagent (Invitrogen; Thermo Fisher Scientific, Inc.). The ratio of absorbance at 260 and $280 \mathrm{~nm}$ was used to access the purity of RNA and RiboGreen $^{\text {TM }}$ used for RNA quantification based on the RiboGreen RNA quantitation assay. Subsequently, reverse transcribed into cDNA using the RevertAid First Strand
Table I. Primer sequences used in reverse transcription-quantitative polymerase chain reaction.

\begin{tabular}{lcc}
\hline Gene & & Primer sequence $\left(5^{\prime} \rightarrow 3^{\prime}\right)$ \\
\hline HMGA1 & F: & TCCAAGAAGGCATCCGCATT \\
& R: & AGGAGCAGGTGGAAGAGTGA \\
ILK & F: & TTTGCAGTGCTTCTGTGGGAA \\
& R: & CTACTTGTCCTGCATCTTCTC \\
MMP2 & F: & GATGTTGTCTTGGAGCGTGC \\
& R: & CTGGGGCAGTCCAAAGAACT \\
MMP9 & F: & TGTACCGCTATGGTTACACTCG \\
& R: & GGCAGGGACAGTTGCTTCT \\
CyclinD1 & F: & CAGAAGAGCGCGAGGGAG \\
& R: & TCGTTGAGGAGGTTGGCATC \\
c-Myc & F: & GGACTTGTTGCGGAAACGAC \\
& R: & CTCAGCCAAGGTTGTGAGGT \\
GAPDH & F: & TGCACCACCAACTGCTTAGC \\
& R: & GGCATGGACTGTGGTCATGAG
\end{tabular}

F, Forward primer; HMGA1, high mobility group AT-hook 1; ILK, integrin-linked kinase; MMP, matrix metalloproteinase; R, reverse primer.

cDNA Synthesis kit (Fermentas; Thermo Fisher Scientific, Inc.). qPCR was performed using SYBR-Green PCR Master Mix (Tiangen Biotech Co., Ltd., Beijing, China) and an ABI 7900 Real-Time PCR System (Applied Biosystems; Thermo Fisher Scientific, Inc.). GAPDH was used as an internal control. Primer sequences used for qPCR are shown in Table I. Relative expression levels (represented as fold change) of the target genes were calculated using the $2^{-\Delta \Delta \mathrm{Cq}}$ method (19). RNA extraction, cDNA synthesis, and were qPCR performed according to the manufacturer's protocols. The PCR program was at $98^{\circ} \mathrm{C}$ for $5 \mathrm{~min}$ on the initial cycle then $30 \mathrm{sec}$ rest followed by 25 cycles, annealing was performed at $72^{\circ} \mathrm{C}$ for $30 \mathrm{sec}$, extension temperature was settled at $72^{\circ} \mathrm{C}$ for $15 \mathrm{sec}$ per $\mathrm{kb}$ and final extension was at $68^{\circ} \mathrm{C}$ for $5 \mathrm{~min}$. Each experiment was performed in triplicate.

Western blot analysis. Whole-cell protein was extracted (1x $10^{6}$ cells) using Radioimmunoprecipitation Assay Lysis Buffer (Solarbio Science \& Technology Co., Ltd., Beijing, China). Equal amounts $(50 \mu \mathrm{g})$ of proteins, quantified by Bradford assay, were separated by $8-12 \%$ SDS-PAGE and transferred to polyvinylidene difluoride membranes (Millipore; Merck KGaA, Darmstadt, Germany). The membranes were blocked for $1 \mathrm{~h}$ with $5 \%$ bovine serum albumin (Abcam, Cambridge, UK) in Tris-buffered saline containing $0.05 \%$ Tween-20 (TBST) and then incubated at $4{ }^{\circ} \mathrm{C}$ overnight with the following rabbit anti-human primary antibodies: anti-HMGA1 (ab205768; 1:5,000), anti-ILK (ab196013; 1:5,000), anti-Akt (ab81283; 1:5,000), anti-GSK3 $\beta$ (ab32391; 1:5,000), anti-MMP2 (ab92536; 1:5,000), anti-MMP9 (ab38898; 1:1,000), anti-cyclinD1 (ab16663; 1:25) and anti-c-Myc (ab3207; 1:10,000) (all from Abcam); anti-phosphorylated (p)-AKT (Ser473) $(4060 ; 1: 2,000)$ and anti-p-GSK3 $\beta$ (Ser9) $(5558 ; 1: 1,000)$ 
(Cell Signaling Technology, Inc., Danvers, MA, USA); and anti- $\beta$-actin (TA-09, 1:1,000) (Zhongshan Golden Bridge Biotechnology Co., Ltd., Beijing, China). Following primary antibody incubation, the membranes were washed with TBST to remove excess antibodies and incubated with horseradish peroxidase-conjugated goat anti-rabbit (IgG HRP; PV-6001; 1:10,000) and rabbit anti-mouse (IgG HRP; PV-6002; 1:1,000) secondary antibodies (Zhongshan Golden Bridge Biotechnology Co., Ltd.) for $1 \mathrm{~h}$ at room temperature. The signals were visualized using SuperSignal West Pico Chemiluminescent Substrate (Thermo Fisher Scientific, Inc.), and band intensities were quantified by Image J software (National Institutes of Health, Bethesda, MD, USA). $\beta$-actin was used as an internal control.

Cell proliferation assay. MHCC $97 \mathrm{H}$ cells were seeded at $2 \times 10^{3}$ cells/well and incubated at $37^{\circ} \mathrm{C}$ for $12 \mathrm{~h}$ in a 96-well plate. Prior to detection, Cell Counting Kit-8 (CCK-8) Reagent (10 $\mu \mathrm{l} /$ well; Solarbio Science \& Technology Co., Ltd.) was added to each well and cells were incubated for $2 \mathrm{~h}$ at $37^{\circ} \mathrm{C}$ in a $5 \% \mathrm{CO}_{2}$ atmosphere. The absorbance was then measured at $450 \mathrm{~nm}$ using a microplate reader and the OD value of each well was used to represent cell proliferation.

Annexin V-fluorescein isothiocyanate (FITC)/propidium iodide (PI) apoptosis assay. An Annexin V-FITC Apoptosis Detection kit (Beyotime Institute of Biotechnology, Haimen, China) was used strictly according to the manufacturer's protocol to detect apoptosis. Following their respective treatments, aforementioned, MHCC $97 \mathrm{H}$ cells $\left(1 \times 10^{5}\right)$ from each of the seven experimental groups were collected and resuspended in $500 \mu \mathrm{l}$ Binding Buffer. Annexin V-FITC (5 $\mu \mathrm{l})$ and PI $(5 \mu \mathrm{l})$ were added to the cell suspensions and were incubated for $15 \mathrm{~min}$ at room temperature in the dark; the apoptosis rates of these cells were immediately assessed by a FACScan flow cytometry and analyzed using BD FACStation software version 6.1 (BD Biosciences, Franklin Lakes, NJ).

Cell invasion assay. The invasive capabilities of the 7 experimental groups of MHCC97H cells were detected using 24-well Matrigel-coated chambers (pore size, $8 \mu \mathrm{m}$; BD Biosciences). Cells $\left(1 \times 10^{5}\right)$ were resuspended in $200 \mu \mathrm{l}$ serum-free medium and seeded into the upper chamber, and $600 \mu 1$ DMEM containing $10 \%$ FBS was added to the lower chamber as a chemoattractant. Following $24 \mathrm{~h}$ incubation at $37^{\circ} \mathrm{C}$, the cells remaining in the upper chamber were removed with a cotton swab and the cells that migrated to the lower surface of membrane were fixed with $100 \%$ methanol, stained with $0.1 \%$ crystal violet and observed by light and electron microscopy using Gen5 software version 2.0 (BioTek Instruments, Inc., Winooski, VT, USA).

Wound-healing assay for cell migration. Cells ( $1 \times 10^{5}$ cells) were seeded in 6-well plates and grown to confluence $100 \%$ at $37^{\circ} \mathrm{C}$. The monolayer of cells was scratched with a pipette tip to create wound, and the dead cells were washed away with PBS prior to culturing in $10 \%$ FBS supplemented DMEM at $37^{\circ} \mathrm{C}$. Images were captured by light and electron microscopy at 0 and $24 \mathrm{~h}$, and cell migration was assessed by the width of the wound.
Statistical analysis. Results are presented as mean \pm standard deviation of three independent experiments. Statistical significances between different groups were analyzed one-way analysis of variance followed by Tukey comparison test. $\mathrm{P}<0.05$ was considered to indicate a statistically significant difference.

\section{Results}

Alteration of HMGA1, ILK, $p$-Akt and $p$-GSK3 $\beta$ expression in MHCC97H cells treated with shRNA, ILK and/or MK2206. As shown in Fig. 1A, MHCC97H cells transfected with shHMGA1 exhibited a significant reduction in HMGA1 mRNA expression ( $P<0.05$ vs. shControl), even when the same cells expressed the ILK vector or are treated with the Akt-specific inhibitor MK2206. shHMGA1 transfection also resulted in a significant decrease in the level of ILK mRNA expression in MHCC7H cells ( $\mathrm{P}<0.05$ vs. shControl); however, this decrease in expression was recovered by ILK overexpression $(\mathrm{P}<0.05$ vs. shHMGA + EGFP); ShHMGA1 transfection resulted in a great increase in the level of ILK mRNA in MHCC7H cells compared with HMGA1 mRNA ( $\mathrm{P}<0.05$ vs. shHMGA + ILK + MK2206; Fig. 1B). Western blot analysis demonstrated similar results: protein expression levels of HMGA1 and ILK were reduced in cells exposed to shHMGA1, and ILK expression vector was only able to recover the expression of ILK and not HMGA1 (Fig. 1C). The protein expression levels of p-Akt and p-GSK3 $\beta$ were also reduced by shHMGA1 treatment, but were recovered in cells overexpressing of ILK. In MHCC97H cells co-treated with shHMGA1, the ILK expression vector and MK2206, the protein expression levels of HMGA1, p-Akt and p-GSK3 $\beta$ were similar to those cells treated with shHMGA1 only.

HMGA1 participates in MHCC97H cell proliferation and inhibits cell apoptosis through the ILK/Akt/GSK3 $\beta$ signaling pathway. Cell proliferation was detected using the CCK-8 reagent, and the OD450 value of each sample represented the cell viability. As shown in Table II, the OD450 of the Blank control and shControl groups were similar. The OD450 of shHMGA1-treated $\mathrm{MHCC} 97 \mathrm{H}$ cells was obviously less than cells treated with shControl $(\mathrm{P}<0.05)$, but was similar to that of cells co-treated with shHMGA1 + EGFP, shHMGA1 + ILK + DMSO and shHMGA1 + ILK + MK2206. Similarly, the differences were identified between the shHMGA1 + EGFP group and the shHMGA1 + ILK group $(\mathrm{P}<0.05)$, as well as between the shHMGA1 + ILK + DMSO group and the shHMGA1 + ILK + MK2206 group $(\mathrm{P}<0.05)$.

Annexin V-FITC/PI apoptosis detection by flow cytometry revealed that, compared with the Blank control and the shControl groups, MHCC97H cells treated with either shHMGA1 or shHMGA1 + EGFP exhibited a slight increase in the rate of apoptosis $(\mathrm{P}<0.05$; Fig. 2; Table II). Cells in the shHMGA1 + ILK group and the shHMGA1 + ILK + DMSO group were moderate lower than cells in the shHMGA1 group and the shHMGA1 + EGFP group $(\mathrm{P}<0.05)$. The apoptosis rate of cells in the shHMGA1 + ILK + MK2206 group was substantial higher than cells in the shHMGA1 + ILK group or the shHMGA1 + ILK + DMSO group $(\mathrm{P}<0.05)$. 
A

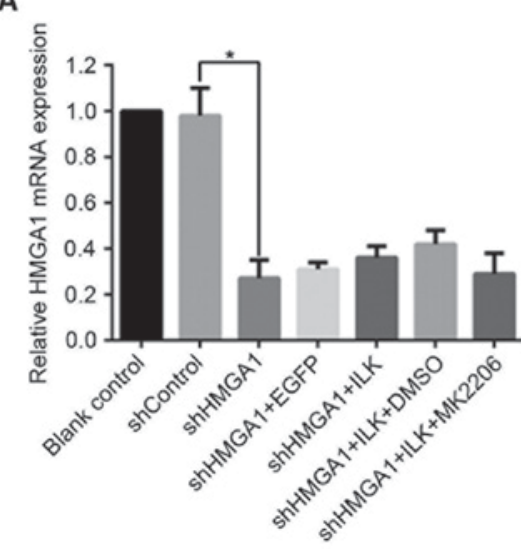

B

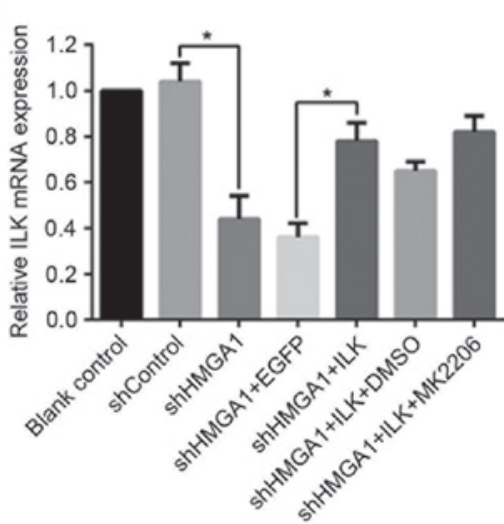

C

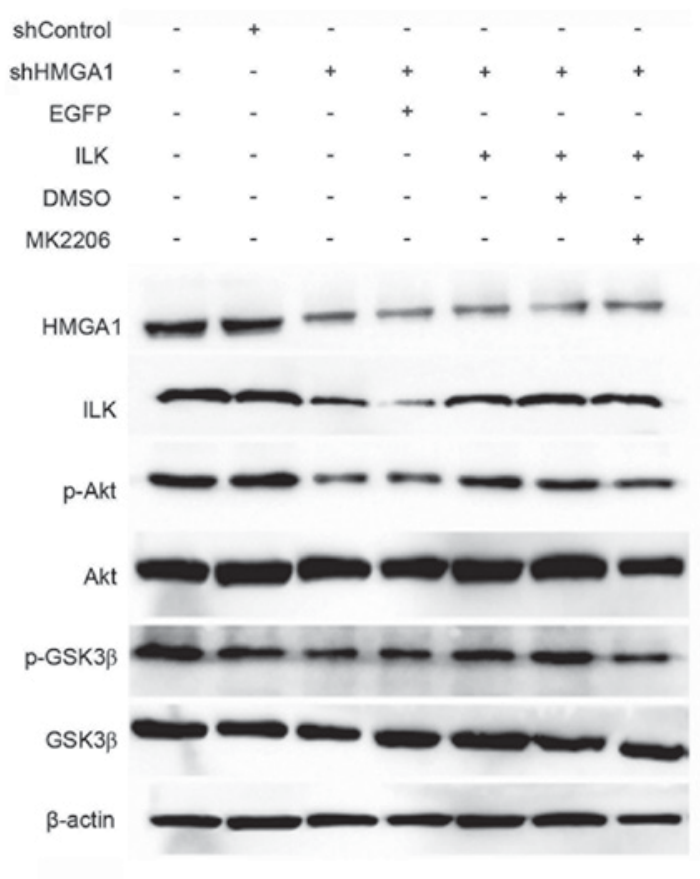

Figure 1. mRNA and protein expression levels of HMGA1, ILK, p-Akt and p-GSK3 $\beta$ in MHCC97H hepatocellular carcinoma cells treated with shHMGA1, ILK expression vector and/or MK2206. Alterations in mRNA expression levels of (A) HMGA1 and (B) ILK were evaluated by reverse transcription-quantitative polymerase chain reaction. ${ }^{*}<<0.05$. (C) Protein expression levels of HMGA1, ILK, total Akt, p-Akt, total GSK3 $\beta$ and p-GSK3 $\beta$ were examined by western blot analysis; GAPDH was used as an internal control. DMSO, dimethylsulfoxide; EGFP, enhanced green fluorescent protein; GSK3 $\beta$, glycogen synthase kinase 3ß; HMGA1, high mobility group AT-hook 1; ILK, integrin-linked kinase; MK2206, an Akt-specific inhibitor; p, phosphorylated; sh, short hairpin RNA.

Table II. Cell proliferation and apoptosis assay results.

\begin{tabular}{lcc}
\hline Group & OD450 & $\begin{array}{c}\text { Apoptosis rate } \\
(\%)^{\mathrm{a}, \mathrm{b}}\end{array}$ \\
\hline Blank control & $1.11 \pm 0.11$ & $3.5 \pm 0.8$ \\
shControl & $1.17 \pm 0.09$ & $4.8 \pm 1.1$ \\
shHMGA1 & $0.36 \pm 0.07^{\mathrm{c}}$ & $32.6 \pm 2.7^{\mathrm{c}}$ \\
shHMGA1 + EGFP & $0.37 \pm 0.02$ & $36.3 \pm 4.5^{\mathrm{c}}$ \\
shHMGA1 + ILK & $0.58 \pm 0.04^{\mathrm{d}}$ & $13.4 \pm 1.1^{\mathrm{d}}$ \\
shHMGA1 + ILK + DMSO & $0.52 \pm 0.03$ & $14.8 \pm 1.2$ \\
shHMGA1 + ILK + MK2206 & $0.39 \pm 0.06^{\mathrm{e}}$ & $23.2 \pm 1.8^{\mathrm{e}}$ \\
\hline
\end{tabular}

${ }^{\text {aResults }}$ are presented as the mean \pm standard deviation. ${ }^{\mathrm{b}} \mathrm{As}$ determined by Annexin V-fluorescein isothiocyanate/propidium iodide staining and flow cytometric analysis. ${ }^{\mathrm{C}} \mathrm{P}<0.05$ vs. Blank control or shControl. ${ }^{\mathrm{d}} \mathrm{P}<0.05$ vs. shHMGA1 + EGFP. ${ }^{\mathrm{e}} \mathrm{P}<0.05$ vs. shHMGA1 + ILK + DMSO. DMSO, dimethylsulfoxide; EGFP, enhanced green fluorescent protein; HMGA1, high mobility group AT-hook 1; ILK, integrin-linked kinase; MK2206, an Akt-specific inhibitor; OD450, optical density at $450 \mathrm{~nm}$; sh, short hairpin RNA.

HMGA1 participates in MHCC97H cell invasion and migration through the ILK/Akt/GSK3 $\beta$ signaling pathway. The invasive capabilities of MHCC97H cells cultured with the various aforementioned treatments were detected with 24-well Matrigel-coated chambers (Fig. 3), and a wound-healing assay was used to examine cell migration (Fig. 4). The invasive and migratory capabilities of MHCC97H cells were suppressed by knockdown of HMGA1 by shRNA transfection; however, cells co-transfected with the ILK expression vector, which increased of ILK protein expression, attenuated this decreased cell migration and invasion. Notably, cells co-cultured with shHMGA1 + ILK + MK2206 exhibited a decrease in invasion and migration, which indicated that MK2206 was able to cancel the effects induced by the upregulation of ILK protein expression. Significant differences were identified in the invasion assay in relation to shHMGA1 vs. shControl, shHMGA1 + ILK vs. shHMGA1 + EGFP, and shHMGA1 + ILK + MK2206 vs. shHMGA1 + ILK + DMSO (P<0.05; Fig. 3B).

HMGA1 serves a role in regulating MMP2, MMP9, CyclinD1, c-Myc expression in MHCC97H cells. As the results of RT-qPCR analysis demonstrate (Fig. 5A-D), the shRNA knockdown of HMGA1 expression in MHCC97H cells led to a significant decrease in mRNA expression levels of MMP2, MMP9, CyclinD1 and C-Myc with the ( $<<0.05$ vs. shControl). These shHMGA1-induced decreases in expression were reversed in MHCC97H cells co-treated with the ILK 
A

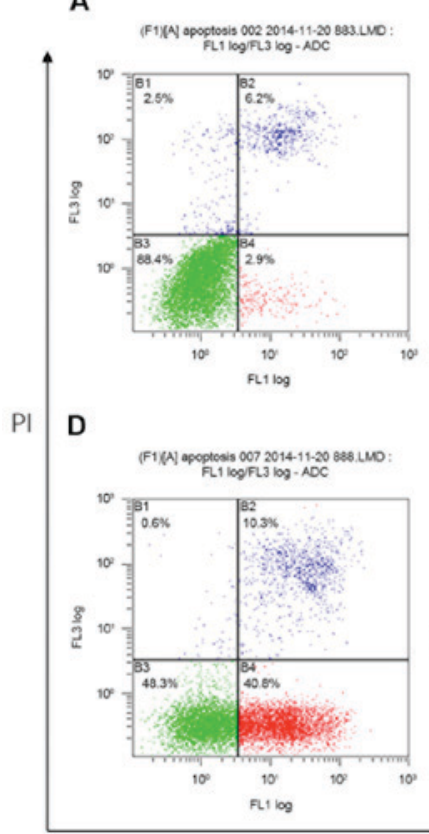

B

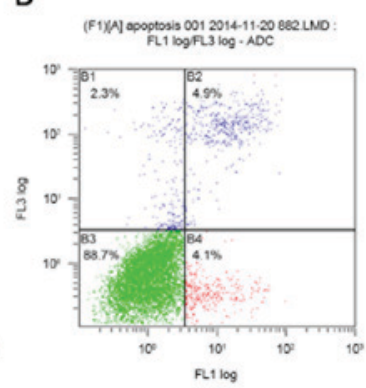

E

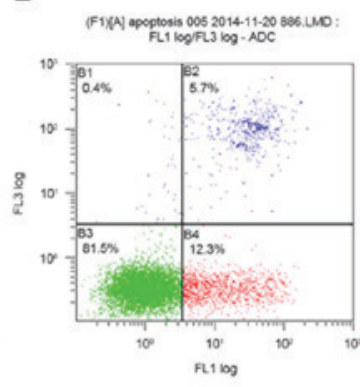

C

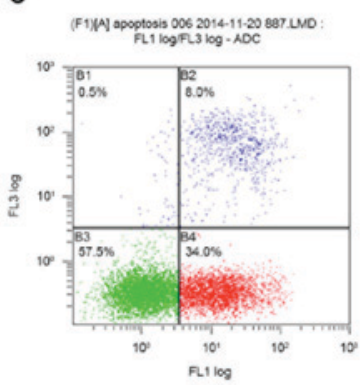

$\mathrm{F}$
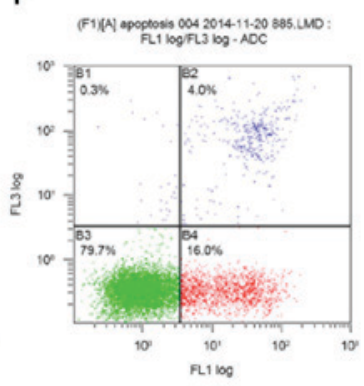

G

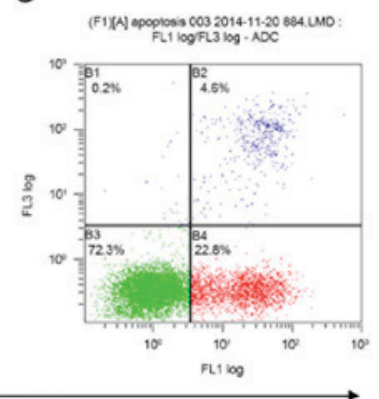

Annexin V-FITC

Figure 2. The effects on apoptosis in MHCC97H hepatocellular carcinoma cells treated with shHMGA1, ILK expression vector and/or MK2206. In each panel, B2 quadrant indicates only PI positive cells that were necrotic and the B4 quadrant indicates live cells. The B1 quadrant indicates Annexin and PI as late apoptosis cells and the B3 quadrant illustrates Annexin as early apoptotic cells. Apoptosis levels were also detected by flow cytometry in each of the seven experimental groups: (A) Blank control group; (B) shControl group; (C) shHMGA1 group; (D) shHMGA1 + EGFP group; (E) shHMGA1 + ILK group; (F) shHMGA1 + ILK + DMSO group; and (G) shHMGA1 + ILK + MK2206 group. DMSO, dimethylsulfoxide; EGFP, enhanced green fluorescent protein; HMGA1, high mobility group AT-hook 1; ILK, integrin-linked kinase; MK2206, an Akt-specific inhibitor; sh, short hairpin RNA.

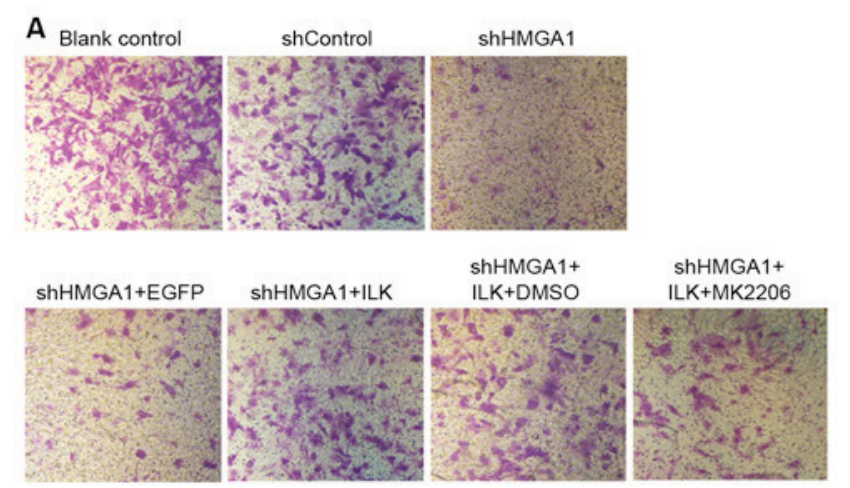

B

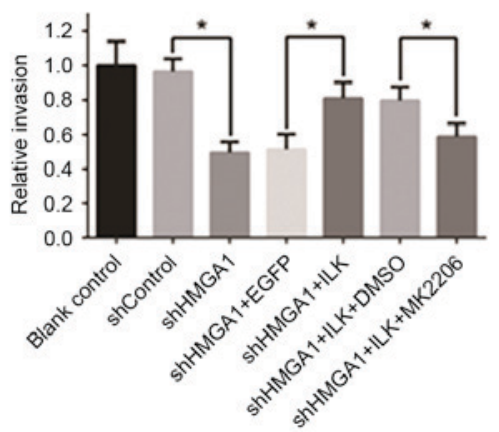

Figure 3. The effects on cell invasiveness in MHCC97H hepatocellular carcinoma cells treated with shHMGA1, ILK expression vector and MK2206. Cell invasion capability under the different conditions was detected using the Transwell method (magnification, x100), followed by (A) crystal violet staining and (B) statistical analysis of the number of migrated cells. Data are expressed as the mean \pm standard deviation; ${ }^{*} \mathrm{P}<0.05$. DMSO, dimethylsulfoxide; EGFP, enhanced green fluorescent protein; HMGA1, high mobility group AT-hook 1; ILK, integrin-linked kinase; MK2206, an Akt-specific inhibitor; sh, short hairpin RNA. expression vector $(\mathrm{P}<0.05$ vs. shHMGA1 + EGFP). MK2206 exposure was able to inhibit the effects of ILK expression in shHMGA1 co-treated cells, and this led to the decreased expression of MMP2, MMP9, CyclinD1 and C-Myc $(\mathrm{P}<0.05$ vs. shHMGA1 + ILK + DMSO). The protein expression levels, as detected by western blot analysis, of MMP2, MMP9, CyclinD1 and C-Myc in MHCC97H cells were similar to their mRNA expression levels in the various treatments, and were influenced by shHMGA1 and ILK expression (Fig. 5E).

\section{Discussion}

An increasing number of studies have indicated that HMGA1 is overexpressed in almost all aggressive cancers, including $\mathrm{HCC}$, and regulates many processes that are characteristically implicated in tumorigenesis $(20,21)$. However, the roles and mechanisms of HMGA1 in HCC pathogenesis remain elusive. The present study provided, to the best of our knowledge, the first evidence that the effects of HMGA1 expression on MHCC97H cell malignant phenotypes are achieved through the ILK/Akt/GSK3 $\beta$ signaling pathway.

Numerous additional studies have demonstrated that ILK also has significant effects on the development and progression of human carcinoma $(11-13,15,18,22)$. ILK serves a crucial role in diverse cellular functions that are associated with cell survival, proliferation, motility, epithelial-mesenchymal transition and angiogenesis (11-13). Akt and GSK3 $\beta$ are two major downstream substrates of the intracellular serine/threonine kinase ILK in cancer cells (14). ILK/Akt/GSK3 $\beta$ signaling has been demonstrated to be a major pathway involved in various cancers (22). It has been reported that ILK was overexpressed 


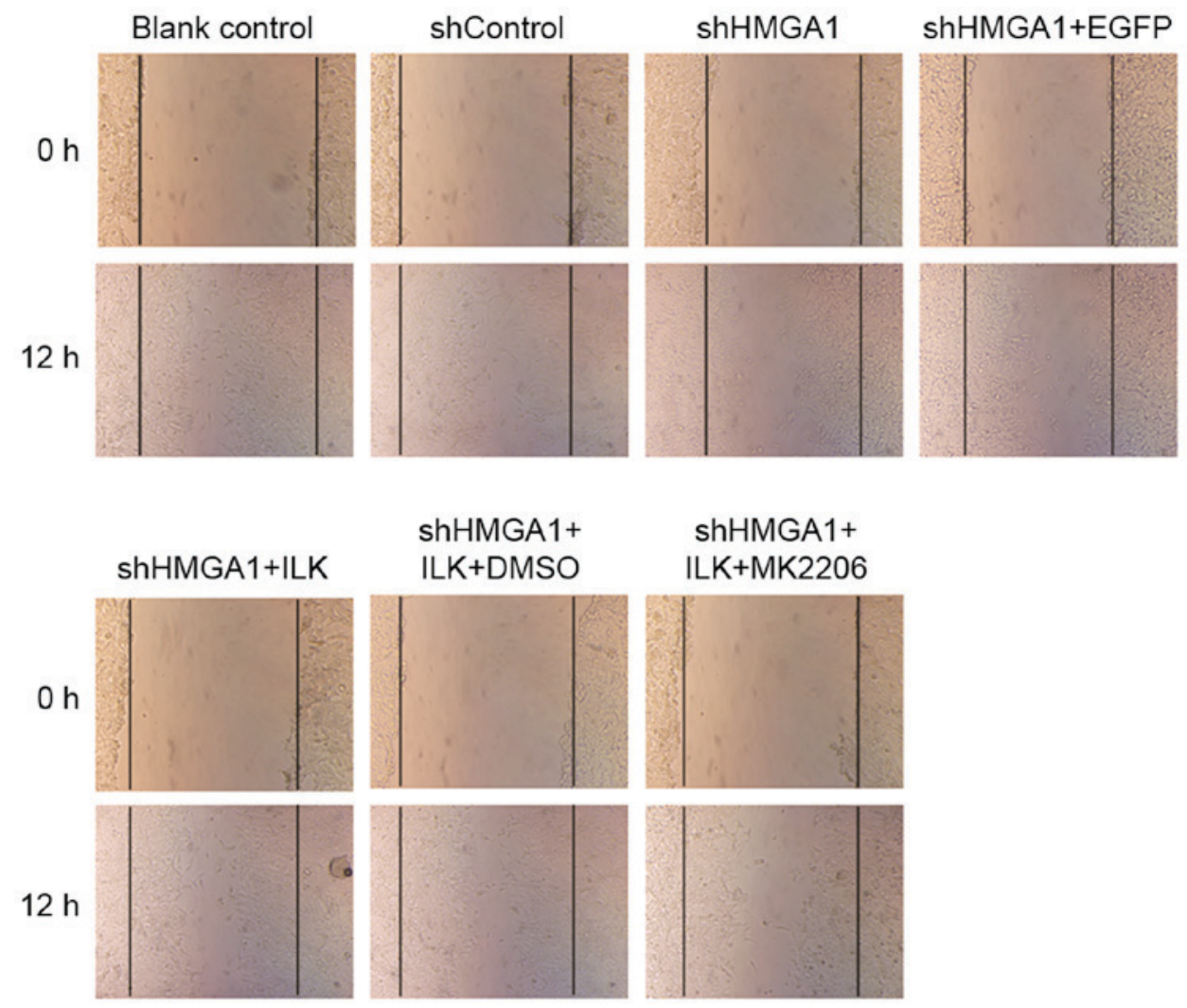

Figure 4. The effects on cell migration in MHCC97H hepatocellular carcinoma cells treated with shHMGA1, ILK expression vector and/or MK2206. Cell migration was examined using a wound-healing assay (magnification, $\mathrm{x} 40$ ). DMSO, dimethylsulfoxide; EGFP, enhanced green fluorescent protein; HMGA1, high mobility group AT-hook 1; ILK, integrin-linked kinase; MK2206, an Akt-specific inhibitor; sh, short hairpin RNA.
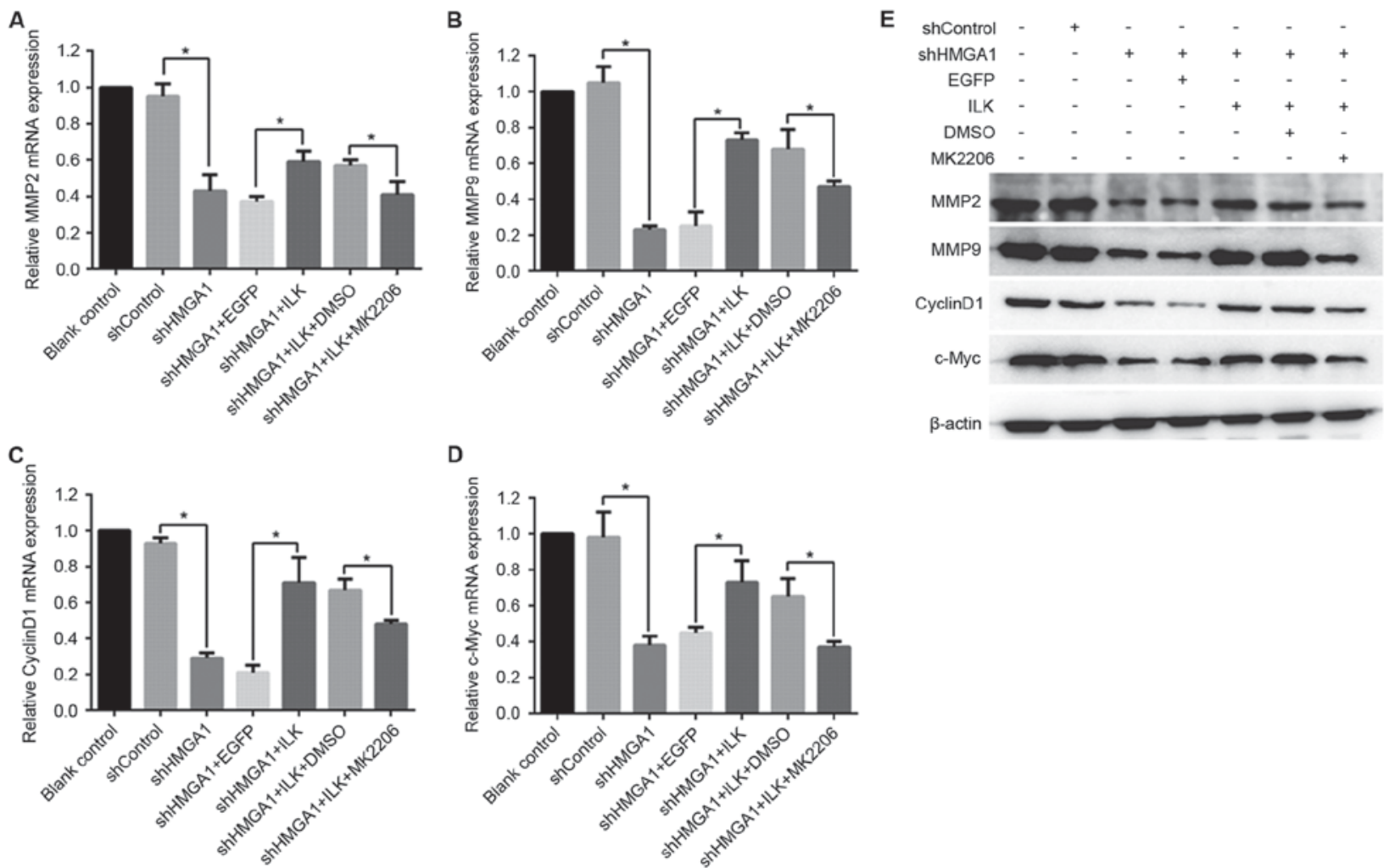

Figure 5. mRNA and protein expression of MMP2, MMP9, CyclinD1 and c-Myc in MHCC97H hepatocellular carcinoma cells treated with shHMGA1, ILK expression vector and/or MK2206. Changes in mRNA expression levels were determined by reverse transcription-quantitative polymerase chain reaction for (A) MMP2, (B) MMP9, (C) CyclinD1 and (D) c-Myc. "P<0.05. (E) Protein expression levels of MMP2, MMP9, CyclinD1 and c-Myc were detected by western blot analysis; $\beta$-actin was used as an internal control. DMSO, dimethylsulfoxide; EGFP, enhanced green fluorescent protein; HMGA1, high mobility group AT-hook 1; ILK, integrin-linked kinase; MK2206, an Akt-specific inhibitor; MMP, matrix metalloproteinase; sh, short hairpin RNA. 
during liver oncogenesis and cirrhosis, and this overexpression was strongly associated with Akt activation (18). One study revealed that ILK knockdown significantly suppressed HCC cell growth, motility and invasion in vitro and inhibited tumorigenesis in vivo with reduced p-Akt (Ser473) expression (17). Another study demonstrated that HCC cell lines exhibited increased sensitivity to epidermal growth factor receptor inhibitors and decreased AKT activation when cells were transformed with a kinase-inactive ILK (23). Taken together, these data suggested that the regulatory function of ILK in HCC pathogenesis may involve the Akt pathway.

HMGA1 and ILK serve important roles in tumor development and both are highly expressed in $\operatorname{HCC}(15,22,24,25)$. The present study aimed to determine whether HMGA1 regulated the ILK/Akt/GSK3 $\beta$ signaling pathway in MHCC97H cells. The results demonstrated that ILK expression levels were decreased by shRNA-mediated knockdown of HMGA1 expression, but were not affected by treatment with the Akt inhibitor MK2206. In addition, HMGA1 knockdown suppressed Akt and GSK3 $\beta$ phosphorylation, which was recovered in MHCC97H cells transfected with an ILK expression vector. Co-treatment with MK2206 was able to disrupt the effects of ILK overexpression, and reduced HMGA1 expression levels caused by shHMGA1 were unaffected by ILK/MK2206 treatment. These data indicated that HMGA1 may be an upstream element in the ILK/Akt/GSK3 $\beta$ pathway, which carries out the regulatory functions in $\mathrm{MHCC} 97 \mathrm{H}$ cells.

Based on the well-defined role of ILK in human malignancy, the present study hypothesized that the promoting effects of HMGA1 on cell malignant phenotypes may at least partially be mediated by ILK. This theory was supported by the results demonstrating that the knockdown of HMGA1 expression was able to inhibit the proliferative and invasive ability of $\mathrm{MHCC} 97 \mathrm{H}$ cells and to induce apoptosis, whereas the effects of shHMGA1 were reversed by ILK overexpression, which itself was subverted when cells were co-treated with MK2206.

To further define the downstream molecular mechanisms underlying HMGA1/ILK/Akt/GSK3 $\beta$-axis-mediated cancer cell progression, the present study analyzed the mRNA and protein expressions of MMP2, MMP9, CyclinD1 and c-Myc, which have been identified as targets of the Akt/GSK3 $\beta$ pathway (26-28). MMPs, particularly MMP2 and MMP9, are well-known extracellular matrix-degrading enzymes that serve important roles in tumor invasion and metastasis (29). CyclinD1 has been revealed to be overexpresses in various tumors and promotes the G1/S shift that leads to cell proliferation $(30,31)$. The multifunctional, nuclear phosphoprotein c-Myc is involved in cell cycle progression, apoptosis and cellular transformation (32). Results from the present study demonstrated that the alterations in MMP2, MMP9, CyclinD1 and c-Myc expression correlated with the shHMGA1-induced changes to MHCC97H cells malignant phenotype, which suggested that HMGA1 may promote HCC growth and metastasis via activation of ILK/Akt/GSK3 $\beta$ signaling and subsequent upregulation of MMP2, MMP9, CyclinD1 and c-Myc expression in MHCC97H cells.

In conclusion, the results from the present study suggested that HMGA1 participates in the survival and metastasis of HCC cells through ILK/Akt/GSK3 $\beta$ signaling, and that
MMP2, MMP9, CyclinD1 and c-Myc are part of the downstream effectors of this pathway. These data provide the basis for exploring the application of HMGA1 inhibition as a therapy for patients with HCC and a new treatment strategy to prevent HCC development.

\section{References}

1. Jemal A, Bray F, Center MM, Ferlay J, Ward E and Forman D: Global cancer statistics. CA Cancer J Clin 61: 69-90, 2011.

2. Maluccio M and Covey A: Recent progress in understanding, diagnosing, and treating hepatocellular carcinoma. CA Cancer J Clin 62: 394-399, 2012.

3. Teufel A, Staib F, Kanzler S, Weinmann A, Schulze-Bergkamen H and Galle PR: Genetics of hepatocellular carcinoma. World J Gastroenterol 13: 2271-2282, 2007.

4. Shah SN and Resar LM: High mobility group A1 and cancer: Potential biomarker and therapeutic target. Histol Histopathol 27: 567-579, 2012.

5. Jung KY, Chen K, Kretzler M and Wu C: TGF-beta1 regulates the PINCH-1-integrin-linked kinase-alph-aparvin complex in glomerular cells. J Am Soc Nephrol 18: 66-73, 2007.

6. Attwell S, Mills J, Troussard A, Wu C and Dedhar S: Integration of cell attachment, cytoskeletal localization, and signaling by integrin-linked kinase (ILK), CH-ILKBP, and the tumor suppressor PTEN. Mol Biol Cell 14: 4813-4825, 2003.

7. Li Z, Nie F, Wang S and Li L: Histone H4 Lys 20 monomethylation by histone methylase SET8 mediates Wnt target gene activation. Proc Natl Acad Sci USA 108: 3116-3123, 2011.

8. Curtin JC and Lorenzi MV: Drug discovery approaches to target Wnt signaling in cancer stem cells. Oncotarget 1: 552-566, 2010.

9. Chang ZG, Yang LY, Wang W, Peng JX, Huang GW, Tao YM and Ding X: Determination of high mobility group A1 (HMGA1) expression in hepatocellular carcinoma: A potential prognostic marker. Dig Dis Sci 50: 1764-1770, 2005.

10. Hannigan GE,Leung-Hagesteijn C, Fitz-Gibbon L, Coppolino MG, Radeva G, Filmus J, Bell JC and Dedhar S: Regulation of cell adhesion and anchorage-dependent growth by a new beta 1-integrin-linked protein kinase. Nature 379: 91-96, 1996.

11. Novak A, Hsu SC, Leung-Hagesteijn C, Radeva G, Papkoff J, Montesano R, Roskelley C, Grosschedl R and Dedhar S: Cell adhesion and the integrin-linked kinase regulate the LEF-1 and beta-catenin signaling pathways. Proc Natl Acad Sci USA 95: 4374-4379, 1998 .

12. Attwell S, Roskelley $C$ and Dedhar S: The integrin-linked kinase (ILK) suppresses anoikis. Oncogene 19: 3811-3815, 2000.

13. Troussard AA, Costello P, Yoganathan TN, Kumagai S, Roskelley CD and Dedhar S: The integrin linked kinase (ILK) induces an invasive phenotype via AP-1 transcription factor-dependent upregulation of matrix metalloproteinase 9 (MMP-9). Oncogene 19: 5444-5452, 2000.

14. Delcommenne M, Tan C, Gray V, Rue L, Woodgett J and Dedhar S: Phosphoinositide-3-OH kinase-dependent regulation of glycogen synthase kinase 3 and protein kinase B/AKT by the integrin-linked kinase. Proc Natl Acad Sci USA 95: 11211-11216, 1998.

15. Tan C, Cruet-Hennequart S, Troussard A, Fazli L, Costello P, Sutton K, Wheeler J, Gleave M, Sanghera J and Dedhar S: Regulation of tumor angiogenesis by integrin-linked kinase (ILK). Cancer Cell 5: 79-90, 2004.

16. Reeves R, Edberg DD and Li Y: Architectural transcription factor HMGI(Y) promotes tumor progression and mesenchymal transition of human epithelial cells. Mol Cell Biol 21: 575-594, 2001.

17. Chan J, Ko FC, Yeung YS, Ng IO and Yam JW: Integrin-linked kinase overexpression and its oncogenic role in promoting tumorigenicity of hepatocellular carcinoma. PLoS One 6: e16984, 2011.

18. Peroukides S, Bravou V, Varakis J, Alexopoulos A, Kalofonos H and Papadaki H: ILK overexpression in human hepatocellular arcinoma and liver cirrhosis correlates with activation of Akt. Oncol Rep 20: 1337-1344, 2008.

19. Livak KJ and Schmittgen TD: Analysis of relative gene expression data using real-time quantitative PCR and the 2(-Delta Delta C(T)) Method. Methods 25: 402-408, 2001.

20. Fusco A and Fedele M: Roles of HMGA proteins in cancer. Nat Rev Cancer 7: 899-910, 2007.

21. Fedele M and Fusco A: HMGA and cancer. Biochim Biophys Acta 1799: 48-54, 2010. 
22. Persad S and Dedhar S: The role of integrin-linked kinase (ILK) in cancer progression. Cancer Metastasis Rev 22: 375-384, 2003.

23. Fuchs BC, Fujii T, Dorfman JD, Goodwin JM, Zhu AX, Lanuti M and Tanabe KK: Epithelial-to-mesenchymal transition and integrin-linked kinase mediate sensitivity to epidermal growth factor receptor inhibition in human hepatoma cells. Cancer Res 68: 2391-2399, 2008.

24. McDonald PC, Oloumi A, Mills J, Dobreva I, Maidan M, Gray V, Wederell ED, Bally MB, Foster LJ and Dedhar S: Rictor and integrin-linked kinase interact and regulate Akt phosphorylation and cancer cell survival. Cancer Res 68: 1618-1624, 2008.

25. Zheng Y, Ritzenthaler JD, Sun X, Roman J and Han S: Prostaglandin E2 stimulates human lung carcinoma cell growth through induction of integrin-linked kinase: The involvement of EP4 and Sp1. Cancer Res 69: 896-904, 2009.

26. Liang J and Slingerland JM: Multiple roles of the PI3K/PKB (Akt) pathway in cell cycle progression. Cell Cycle 2: 339-345, 2003.

27. Wang S and Basson MD: Integrin-linked kinase: A multi-functional regulator modulating extracellular pressure-stimulated cancer cell adhesion through focal adhesion kinase and AKT. Cell Oncol 31: 273-289, 2009.
28. Pontier SM, Huck L, White DE, Rayment J, Sanguin-Gendreau V, Hennessy B, Zuo D, St-Arnaud R, Mills GB, Dedhar S, et al: Integrin-linked kinase has a critical role in ErbB2 mammary tumor progression: Implications for human breast cancer. Oncogene 29: 3374-3385, 2010.

29. Weaver AM: Invadopodia: Specialized cell structures for cancer invasion. Clin Exp Metastasis 23: 97-105, 2006.

30. Attwooll C, Lazzerini Denchi E and Helin K: The E2F family: Specific functions and overlapping interests. EMBO J 23: 4709-4716, 2004.

31. Hulit J, Lee RJ, Russell RG and Pestell RG: ErbB-2-induced mammary tumor growth: The role of cyclinDl and p27kipl. Biochem Pharmacol 64: 827-836, 2002.

32. McMahon SB: MYC and the control of apoptosis. Cold Spring Harb Perspect Med 4: a014407, 2014. 